\title{
Some Recent Developments of Microstrip Antenna
}

\author{
Yong Liu, Li-Ming Si, Meng Wei, Pixian Yan, Pengfei Yang, Hongda Lu, Chao Zheng, \\ Yong Yuan, Jinchao Mou, Xin Lv, and Housjun Sun
}

Department of Electronic Engineering, School of Information and Electronics, Beijing Institute of Technology, Beijing 100081, China

Correspondence should be addressed to Yong Liu, fatufo@bit.edu.cn

Received 12 August 2011; Revised 23 November 2011; Accepted 2 January 2012

Academic Editor: Zhongxiang Q. Shen

Copyright ( $) 2012$ Yong Liu et al. This is an open access article distributed under the Creative Commons Attribution License, which permits unrestricted use, distribution, and reproduction in any medium, provided the original work is properly cited.

\begin{abstract}
Although the microstrip antenna has been extensively studied in the past few decades as one of the standard planar antennas, it still has a huge potential for further developments. The paper suggests three areas for further research based on our previous works on microstrip antenna elements and arrays. One is exploring the variety of microstrip antenna topologies to meet the desired requirement such as ultrawide band (UWB), high gain, miniaturization, circular polarization, multipolarized, and so on. Another is to apply microstrip antenna to form composite antenna which is more potent than the individual antenna. The last is growing towards highly integration of antenna/array and feeding network or operating at relatively high frequencies, like sub-millimeter wave or terahertz $(\mathrm{THz})$ wave regime, by using the advanced machining techniques. To support our points of view, some examples of antennas developed in our group are presented and discussed.
\end{abstract}

\section{Introduction}

The concept of microstrip antenna was first introduced in the 1950 s [1]. However, this idea had to wait nearly 20 years to be realized after the development of the printed circuit board (PCB) technology in the 1970s [2, 3]. Since then, microstrip antennas are considered as the most common types of antennas due to their obvious advantages of light weight, low cost, low profile, planar configuration, easy of conformal, superior portability, suitable for arrays, easy for fabrication, and easy integration with microwave monolithic integrate circuits (MMICs) [4-7]. They have been widely employed for the civilian and military applications such as television, broadcast radio, mobile systems, global positioning system (GPS), radio-frequency identification (RFID), multipleinput multiple-output (MIMO) systems, vehicle collision avoidance system, satellite communications, surveillance systems, direction founding, radar systems, remote sensing, biological imaging, missile guidance, and so on [8].

Despite the many advantages of typical microstrip antennas, they also have three basic disadvantages: narrow bandwidth, low gain, and relatively large size. The narrow bandwidth is one of the main drawbacks of these types of antennas. A straightforward method of improving the bandwidth is increasing the substrate thickness. However, surface wave power increases and radiation power decreases with the increasing substrate thickness [7], which leads to poor radiation efficiency. Thus, various other techniques are presented to provide wide-impedance bandwidths of microstrip antennas, including impedance matching networks using stub $[9,10]$ and negative capacitor/inductor [11], microstrip slot antennas using the $\mathrm{U}, \mathrm{L}, \mathrm{T}$, and inverted $\mathrm{T}$ slots in the ground plane (sometimes termed defected ground structures (DGSs) ) $[12,13]$, surface wave suppressing using magnetodielectric substrate [14] and electromagnetic bandgap (EBG) structures [15], and composite-resonator microstrip antennas using metamaterial resonators [16, 17]. Another problem to be solved is the low gain for conventional microstrip antenna element. Cavity backing has been used to eliminate the bidirectional radiation, thereby providing higher gain compared with conventional microstrip antenna [18]. Lens covering is an alternative way to achieve gain enhancement. The lens with canonical profile, like elliptical, hemielliptical, hyper-hemispherical, extended hemispherical, used to focus the radiation beam from the radiator elements. The integrated lens microstrip antenna can be treated as composite antenna combined by microstrip radiator elements and dielectric lens, which is very useful for high frequencies $(\mathrm{mm}$, sub-mm, terahertz $(\mathrm{THz})$, and optical waves) applications 
[19]. It is also well known that antenna array is an effective means for improving the gain [20-25].

The last limitation of conventional microstrip antennas is the relatively large size, particularly at lower microwave frequencies, since their operation frequencies are related to the electrical size of antenna. In general, the size of the rectangular microstrip antenna should be of order of a halfguided wavelength. This limitation was mathematically studied by Wheeler [26] and Chu [27]. There have been numerous efforts to minimize the antenna size and obtain the electrically small microstrip antenna with the raised demand towards smaller and smaller wireless devices. Inductive or capacitive loading are effective ways to reduce the size of microstrip antennas [28]. In the former work, we demonstrated that the size of microstrip antenna can be miniaturized using composite metamaterial resonators [16, 17]. Magneto-dielectric substrates have been widely used to miniaturize microstrip antennas due to magnetic substrates and could provide wider bandwidths than dielectric substrates [29-32]. Fractal geometries, which are composed by self-similar structures, have opened an alternative way for antenna miniaturization [33].

From the above discussions, we see that many methods and materials are used to improve the properties of microstrip antennas. However, there should be a relationship among bandwidth, gain, and size of the microstrip antennas. Antenna engineers have recognized that the improvement in one antenna property is frequently accompanied by decline in its other performances. For example, the antenna size is reduced usually at the expense of its bandwidth and gain. Therefore, a more comprehensive consideration must be given on further developments of microstrip antennas.

In this paper, we will suggest three areas for further research based on our previous works on microstrip antenna elements and arrays [16-25, 34-41]. We first note that novel microstrip antenna topologies are proposed to meet the desired requirement of variety of potential wireless applications, such as ultrawide band (UWB), high gain, miniaturization, circular polarization, multipolarized, and so on. Next, we discuss the composite antennas based on microstrip antennas which have more potent than each individual antenna. Finally, with the development of micro-/nanomachining techniques, antennas/arrays with highly integration and with highly operating frequencies are discussed. We present some examples of antennas developed in our group to support our points of view.

\section{Variety of Microstrip Antenna Topologies}

Microstrip antennas have extensively used in commercial and military applications due to their attractive advantages. However, the traditional microstrip antennas have the impedance bandwidth of only a few percent and radiation pattern with omnidirection, which obviously does not meet the requirements of various wireless applications. To this end, a wide variety of microstrip antenna topologies, including different microstrip antenna element structures and different microstrip array arrangements, have been studied to meet the desired requirement such as ultrawide band (UWB), high

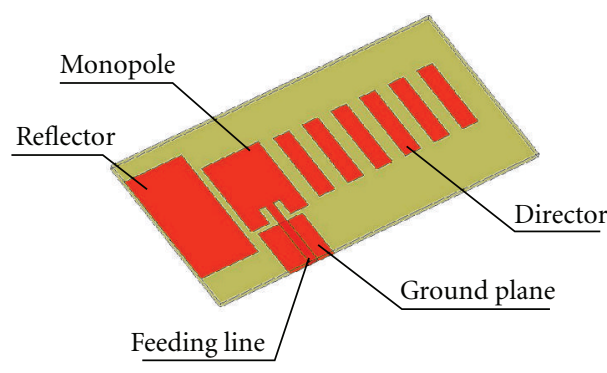

(a) The structure of the quasi-Yagi antenna

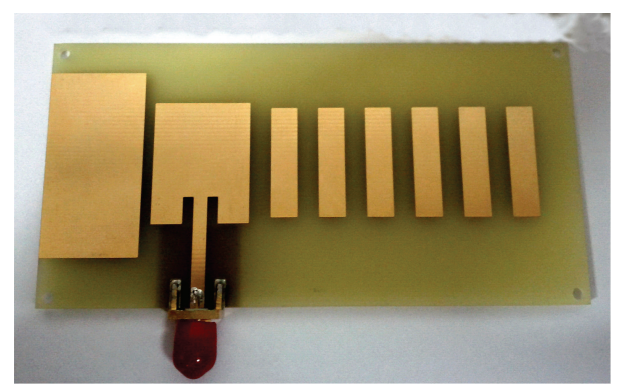

(b) The photograph of the quasi-Yagi antenna

FIgURE 1: Compact broad-band quasi-Yagi antenna.

gain, miniaturization, circular polarization, multipolarized, and so forth.

As we know, microstrip antennas inherently have narrower bandwidth and lower gain compared to conventional bulky antennas. Some microstrip antennas with special topologies, like quasi-Yagi, planar reflector antenna, are proposed to replace the conventional bulky antennas. Here, we will take a quai-Yagi antenna as an example to show how to design a planar microstrip antenna with Yagi-Uda end-fire radiation pattern. In addition, a microstrip array with special array topology is designed to get dual-polarized property.

2.1. Compact Broad-Band Quasi-Yagi Antenna. A novel Sband compact quasi-Yagi antenna has been designed, fabricated and measured by our group, as shown in Figure 1. This antenna is composed of a printed monopole-driven element, a printed reflector element, and six printed director elements.

To explain the end-fire radiation behavior of the quasiYagi antenna, a comparison of radiation patterns, among (1) microstrip monopole only, (2) microstrip monopole and a reflector, (3) microstrip monopole and a director, (4) microstrip monopole and a reflector with one director, and (5) microstrip monopole and a reflector with six director, is shown in Figure 2. We can observe that both the reflector and the director can increase the end-fire radiation, and it could be substantially improved by increasing the number of directors.

The measured VSWR results are shown in Table 1. A bandwidth of $14 \%$ for VSWR less than 1.5 is achieved. The gain of the antenna is above $7.5 \mathrm{dBi}$, as shown in Table 2 . In this design, we see that the microstrip antenna with special topology could be conveniently used to replace the bulky Yagi-Uda antenna. 


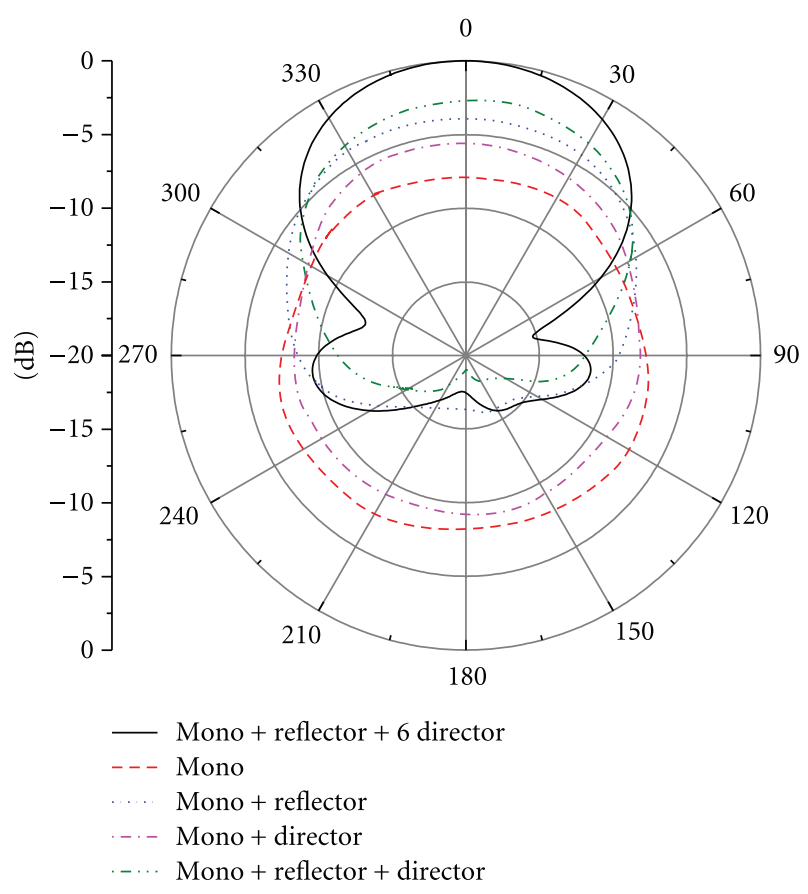

FIgURE 2: Radiation patterns of microstrip monopole only, microstrip monopole and a reflector, microstrip monopole and a director, microstrip monopole and a reflector with one director, and microstrip monopole and a reflector with six director.

TABLE 1: The measured VSWR of the quasi-Yagi antenna.

\begin{tabular}{lcccc}
\hline No. & \multicolumn{4}{c}{ Frequency $(\mathrm{GHz})$} \\
& 3.25 & 3.5 & 3.75 & Inband \\
\hline 1 & 1.36 & 1.34 & 1.47 & $<1.5$ \\
2 & 1.37 & 1.26 & 1.49 & $<1.5$ \\
3 & 1.36 & 1.25 & 1.48 & $<1.5$ \\
\hline
\end{tabular}

TABLE 2: The measured gain of the quasi-Yagi antenna (unit: dBi).

\begin{tabular}{llcl}
\hline No. & \multicolumn{3}{c}{ Frequency $(\mathrm{GHz})$} \\
& 3.25 & 3.5 & 3.75 \\
\hline 1 & 7.57 & 8.73 & 8.35 \\
2 & 7.58 & 8.55 & 8.37 \\
3 & 7.56 & 8.77 & 8.51 \\
\hline
\end{tabular}

2.2. Dual-Polarized Microstrip Antenna Array. The dualpolarized antenna is highly required for the radar, electronic countermeasure, and aerospace systems. It is known that the microstrip antenna can easily be integrated with microwave circuits and feeding network. Here, a novel Ku-band dualpolarization microstrip antenna array with a mixed feeding network, that is, the slot coupled feeding (V-port) and the coplane feeding ( $\mathrm{H}$-port), is designed by our group, as shown in Figure 3. It is a three layers structure: top microstrip patch layer, middle stripline feeding network layer, and bottom coplane microstrip feeding network layer. Through proper array arrangement, very good isolation can be obtained.

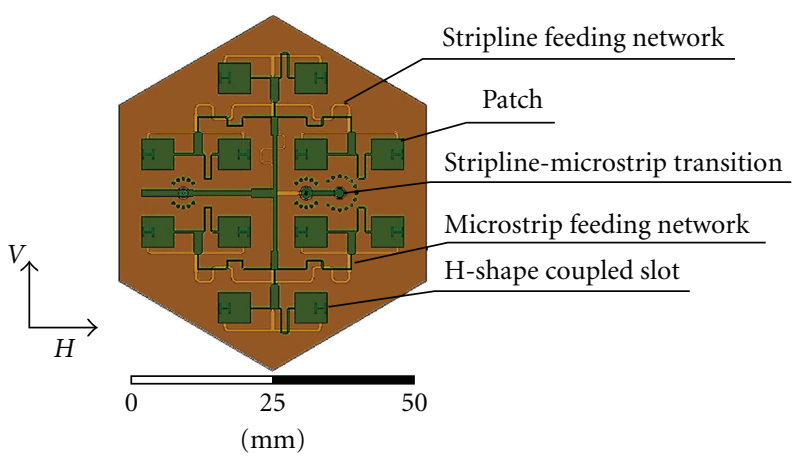

(a) The structure of the dual-polarized microstrip antenna array

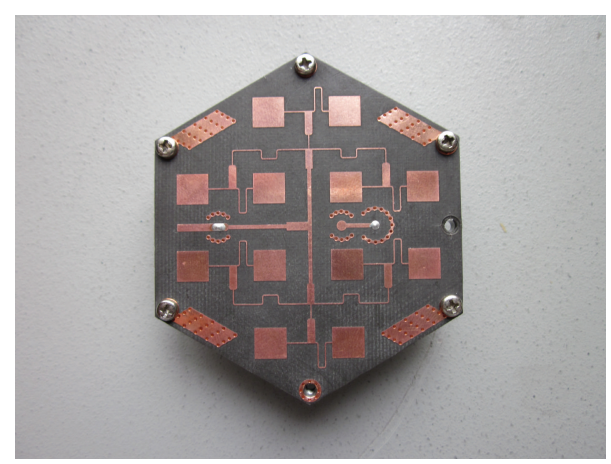

(b) The photograph of the dual-polarized microstrip antenna array

FIGURE 3: Dual-polarized microstrip antenna array.

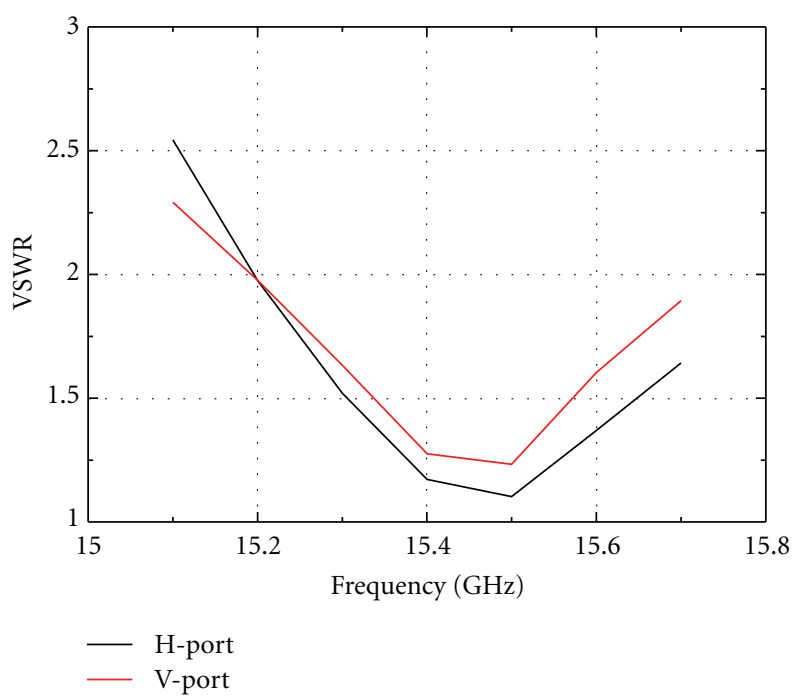

FIGURE 4: The VSWR of the dual-polarized microstrip antenna array.

The VSWR, radiation patterns, and the isolation between two polarizations of the proposed dual-polarized microstrip antenna array are shown in Figures 4, 5, and 6, respectively. The results indicate that this microstrip antenna array has a good impedance matching, good radiation performance, as well as very high isolation (less than $-25 \mathrm{~dB}$ ), which can be an idea candidate for the dual-polarized wireless systems. 


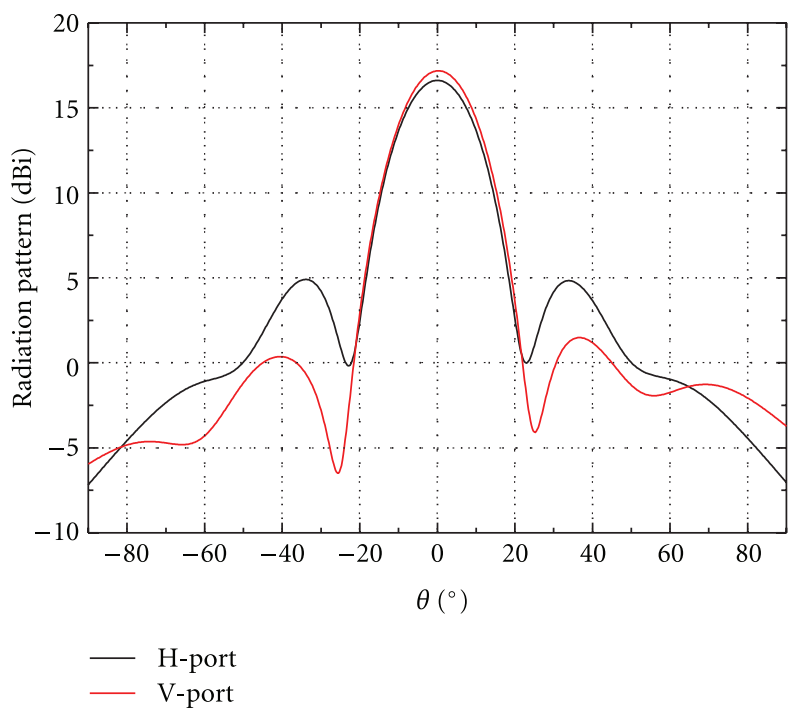

FIGURE 5: The radiation patterns of the dual-polarized microstrip antenna array at the center frequency.

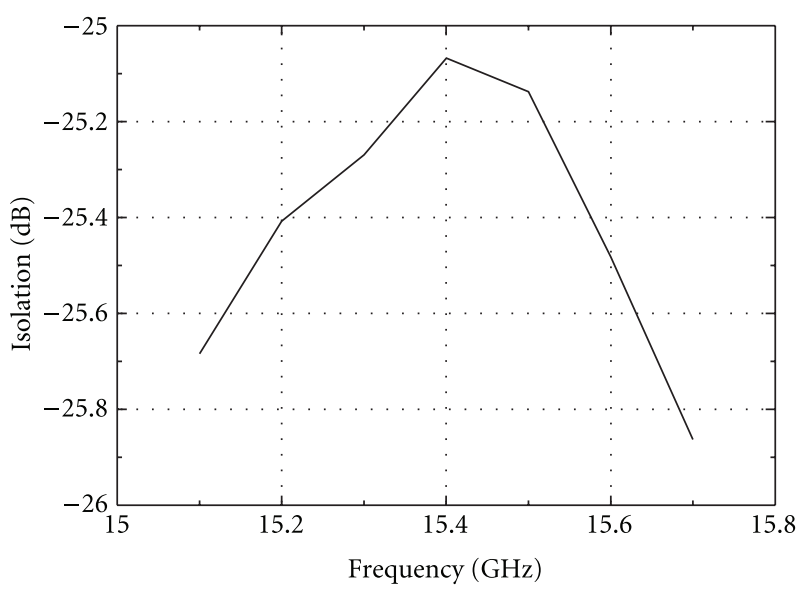

FIGURE 6: The isolation of the dual-polarized microstrip antenna array.

\section{Microstrip-Antenna-Based Composite Antenna}

As many antenna designers have found, it is not easy to design an antenna to meet the user-defined stringent performance requirements demanded by special wireless applications like military radars, surveillances, and missile guidance, if only one type of antenna is considered. This difficulty may require the use of two more different types or structures of antenna elements with different characteristics. Composite antenna formed by two more types or structures of antennas is particularly suitable for these applications due to more advantages offered by different types or structures of antennas. For example, it is a challenging task to use single type of antenna to design a dual-band dual-polarization antenna for satellite digital multimedia broadcast (S-DMB) application [36]. A composite antenna composed with a left-handed circularly polarized (LHCP) microstrip antenna and a linear polarized omnidirectional biconical antenna

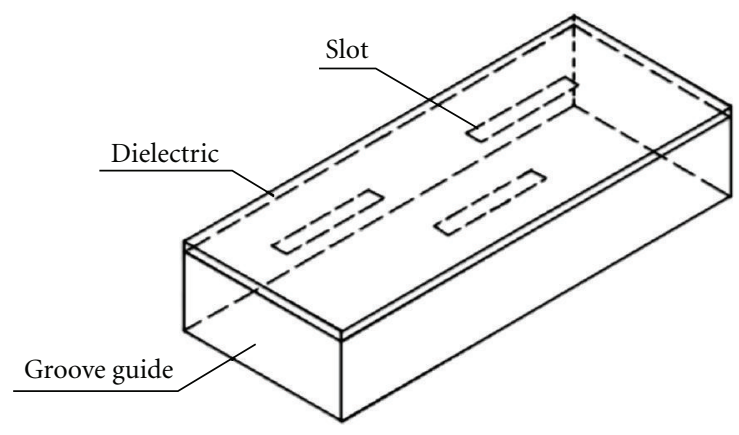

FIgURE 7: The structure of the DCWS.

is proposed by our group to meet this requirement [36]. Another example of composite antenna is comprised of a dielectric lens and microstrip log-period antenna, which has been widely applied to $\mathrm{THz}$ systems (this type of antenna will be further discussed in Section 4.2). Here, we will give an example of composite antenna with "structure composite" method.

3.1. Monopulse Circular-Polarized Dielectric Complex Waveguide Slot Antenna Array. Waveguide slot antenna array has been widely used for wireless system, due to its advantages of high radiation efficiency, high power capacity, and high reliability. However, it is hard to overcome the disadvantage of high cost of fabrication.

One composite antenna with waveguide slot antenna array property, termed dielectric complex waveguide slot (DCWS), is composed with slot microstrip line and groove guide, as shown in Figure 7. The slot microstrip line is formed by a metal clad dielectric substrate and slots etched in the metal. This composite antenna not only maintains the advantages of the traditional waveguide slot antenna array but also has the characteristics of high consistence, easy for fabrication, and low cost. 


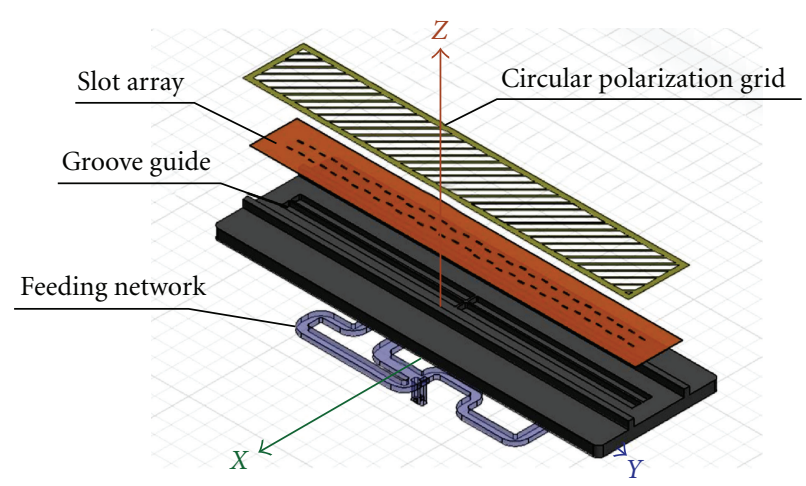

(a) The structure of the monopulse circular-polarized DCWS antenna array (separating view)

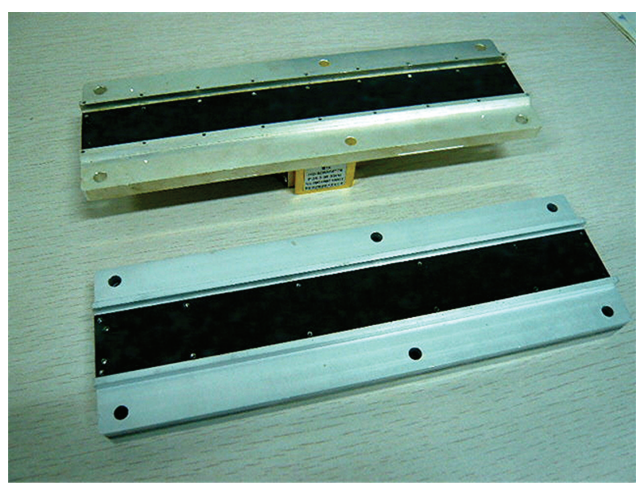

(b) The photograph of the monopulse circular-polarized DCWS antenna array.

FIGURE 8: Ka-band monopulse circular-polarized dielectric complex waveguide slot (DCWS) antenna array.

A Ka-band monopulse circular-polarized dielectric complex waveguide slot (DCWS) antenna array is designed, fabricated, and measured by our group, as shown in Figure 8. It consists of a circular polarization grid, a slot microstrip array, and a groove guide and feeding network. The slot microstrip array is fabricated on a Rogers 5880 film with dielectric constant of 2.2 and the thickness of $0.254 \mathrm{~mm}$. The measured results of VSWR of sum and different port are shown in Figure 9. Figure 10 shows the measured radiation pattern at the center frequency. Some important array performance parameters such as gain, null depth and axial ratio (AR) are also given in Table 3. As shown in the measured results, very good performance can be obtained with the DCWS antenna array. The radiating efficiency of the DCWS antenna array is $80 \%$, which is almost the same as the traditional waveguide slot antenna array. Moreover, the DCWS antenna array has $40 \%$ larger bandwidth than the traditional waveguide slot antenna array.

\section{Highly Integration and Highly Operating Frequency Antennas Based on Advanced Machining Techniques}

It is known that the microstrip antenna was first fabricated using PCB technology in 1970s, nearly 20 years after its

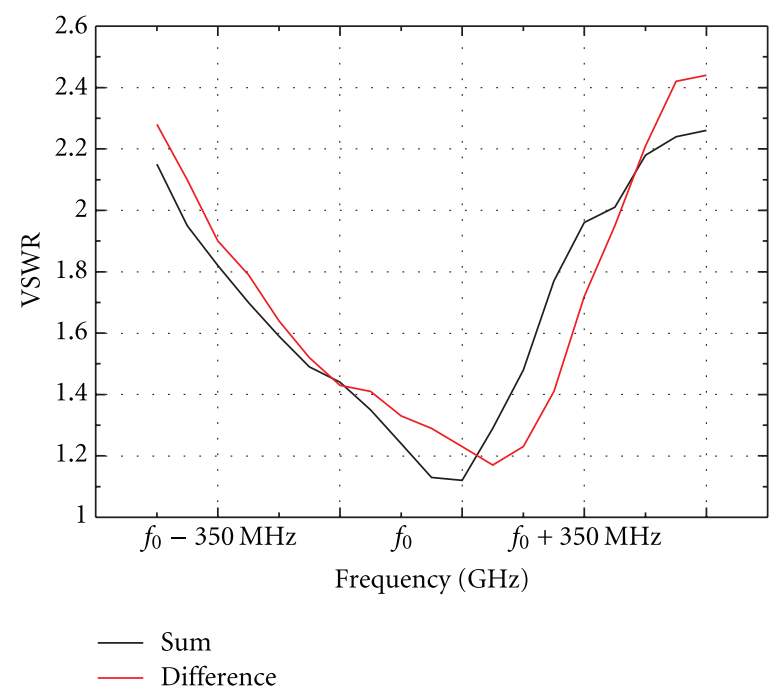

FIGURE 9: The VSWR of sum and difference port of the monopulse circular-polarized DCWS antenna array.

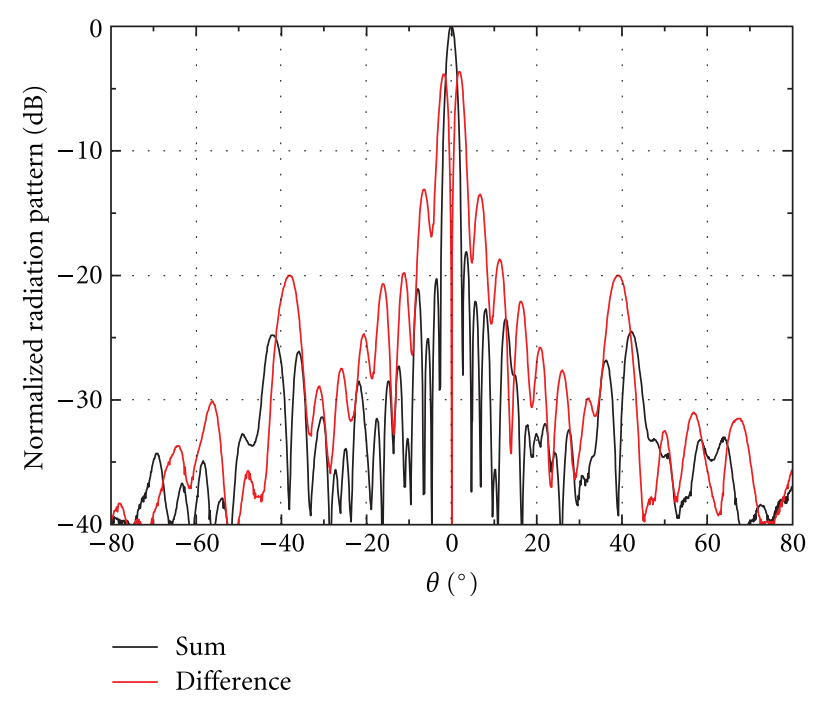

Figure 10: The radiation pattern of the monopulse circularpolarized DCWS antenna array at the center frequency.

concept was first presented in 1950s [1-3]. Clearly, the development of microstrip antennas is closely related with the machining techniques. Recently, various machining techniques, including multilayer printed circuit board (MPCB), complementary metal oxide semiconductor (CMOS), lowtemperature cofired ceramics (LTCC), and micro-electromechanical systems (MEMS), are highly developed, opening opportunities for innovative antennas, such as active antennas, reconfigurable antennas, metamaterial-based antennas, $\mathrm{THz}$ antennas, and so forth. With the availability of highprecision and high-speed advanced machining techniques, microstrip antennas are growing towards highly integration of antenna/array and feed network and operating at relatively high frequencies. Since they are all based on the advanced 


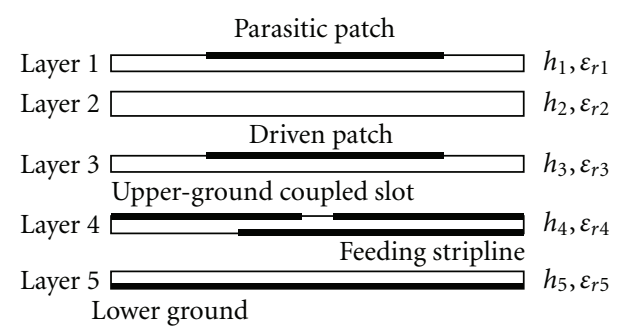

(a) Schematic side view of the structure of the high integrate broadband microstrip antenna array

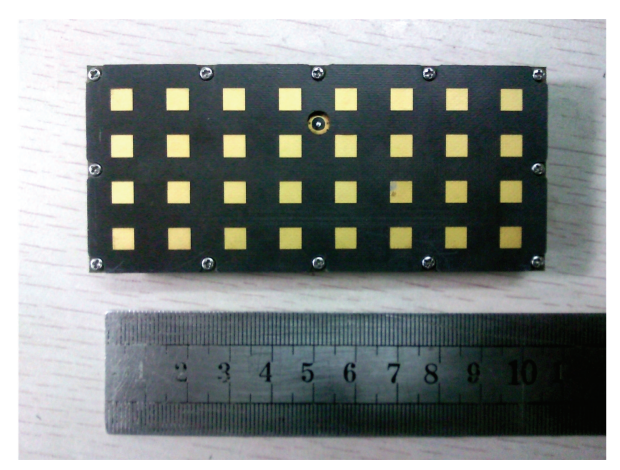

(b) The photograph of the high integrate broadband microstrip antenna array

FIGURE 11: Ku-band high integrate broadband microstrip antenna array using MPCB technology.

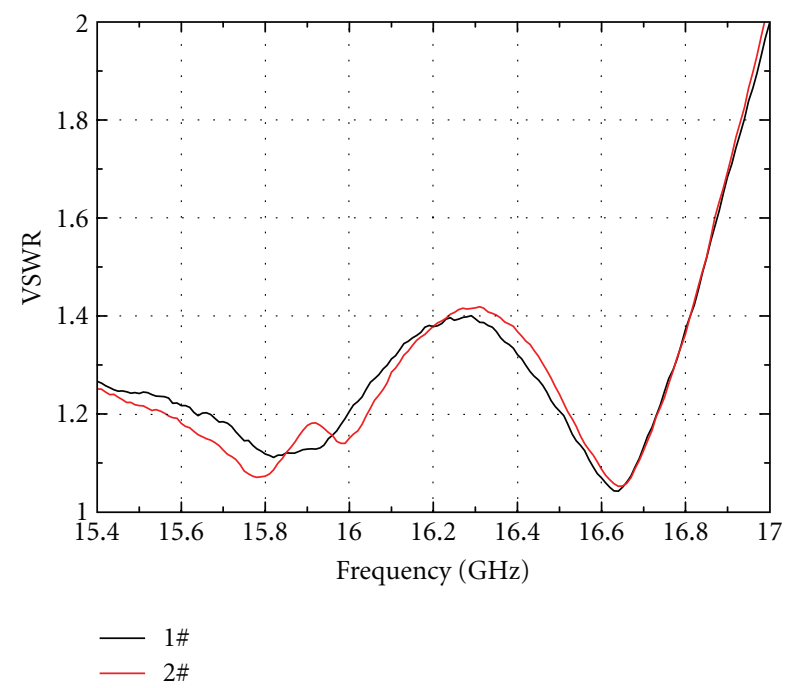

FIGURE 12: The VSWR of the high integrate broad-band microstrip antenna array using MPCB technology.

machining techniques, we suggest that a third research area of microstrip antennas is constantly introducing novel advanced machining techniques. In the following, two examples will be presented to show how important the advanced machining technique is to fabricate microstrip antennas. One is the highly integrate broad-band microstrip antenna array fabricated using MPCB technology. Another is $\mathrm{THz}$ wave planar integrated active microstrip antenna using MEMS technology.

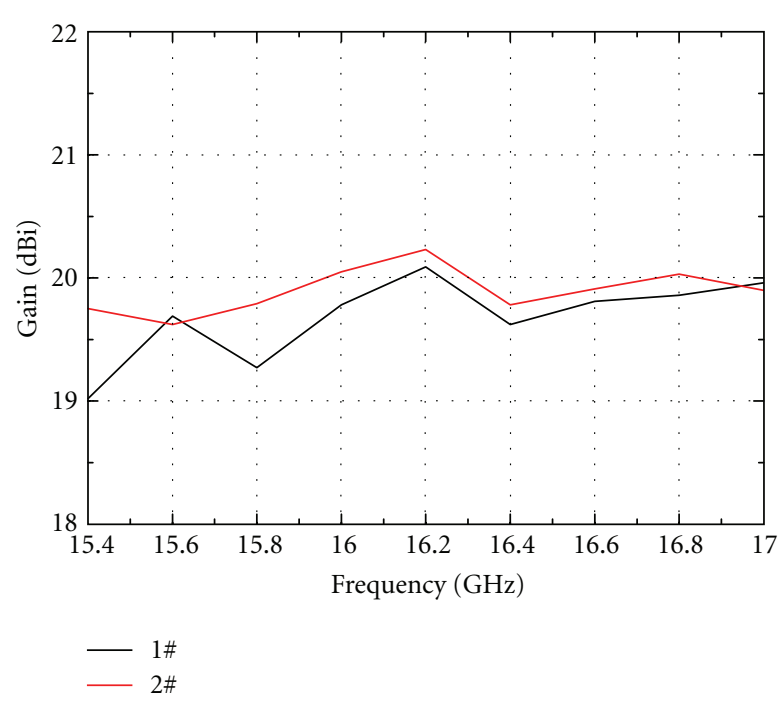

FIGURE 13: The gain of the high integrate broad-band microstrip antenna array using MPCB technology.

TABLE 3: The measured data of the monopulse circular-polarized DCWS antenna array.

\begin{tabular}{lccc}
\hline Fre. $(\mathrm{GHz})$ & Gain $(\mathrm{dBi})$ & Null depth $(\mathrm{dB})$ & AR $(\mathrm{dB})$ \\
\hline$f_{0}-0.2$ & 22.8 & -37.3 & 3.8 \\
$f_{0}$ & 21.9 & -29.9 & 2.9 \\
$f_{0}+0.2$ & 22.1 & -26 & 4.1 \\
\hline
\end{tabular}

4.1. High Integrate Broad-Band Microstrip Antenna Array Using Multilayer Printed Circuit Board (MPCB) Technology. Recently, with the development of the multilayer printed circuit board (MPCB) technology, the microstrip antennas can be designed and fabricated from one-dimensional (1D) to $2 \mathrm{D}$ and even $3 \mathrm{D}$ structures.

Based on the MPCB technology, a high integrated broadband Ku-band microstrip antenna array is designed, fabricated, and measured by our group, as shown in Figure 11. This antenna consists of a parasitic patch, a driven patch, a stripline feeding network, a broad-band coaxial line to stripline transition, some buried screw holes, and some via holes. The feeding network is integrated in the bottom of the substrate of the antenna. As all of the structures fabricated at once, the accuracy and the uniformity can be assured. Two antennas of this type are measured. The measured VSWR, gain, and radiation pattern at the center frequency are shown in Figures 12, 13, and 14, respectively. The measured results show that this antenna maintains good radiation and matching performances with relative bandwidth of $13 \%$. They have also shown good uniformity by using MPCB technology.

\subsection{THz Wave Planar Integrated Active Microstrip Antenna} Using Micro-Electromechanical Systems (MEMSs) Technology. $\mathrm{THz}$ waves typically include frequencies between $0.1 \mathrm{THz}$ and $10 \mathrm{THz}$. THz technology is now becoming a promising technology which has potential applications in many fields, such as short-range communication, biosensor, imaging, 


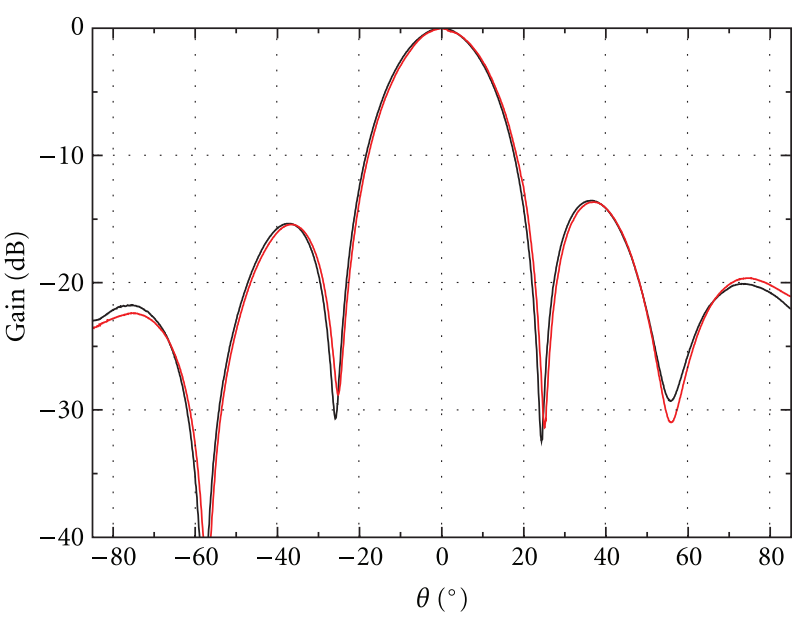

(a) E-plane

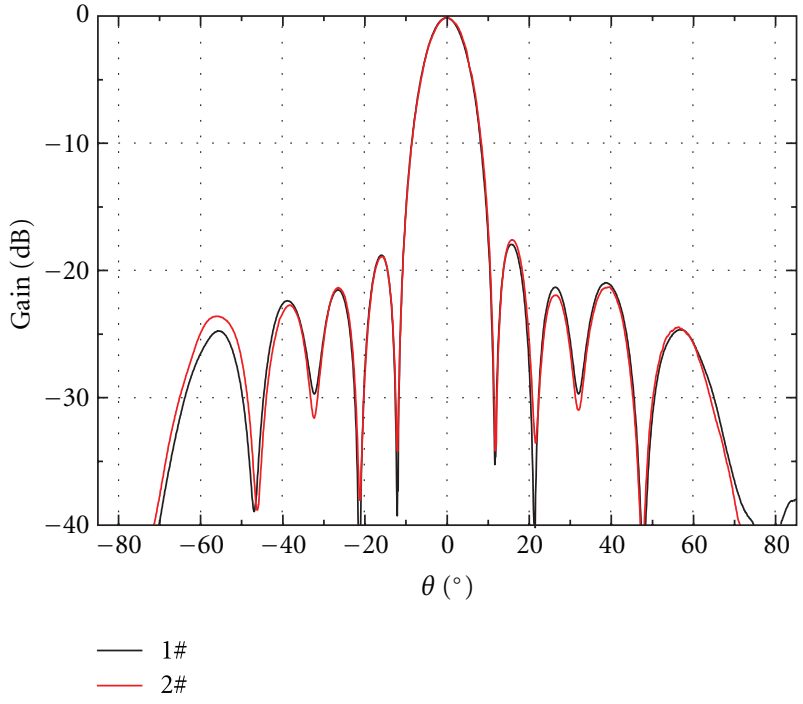

(b) H-plane

FIGURE 14: The radiation pattern of the high integrate broad-band microstrip antenna array using MPCB technology at the center frequency.

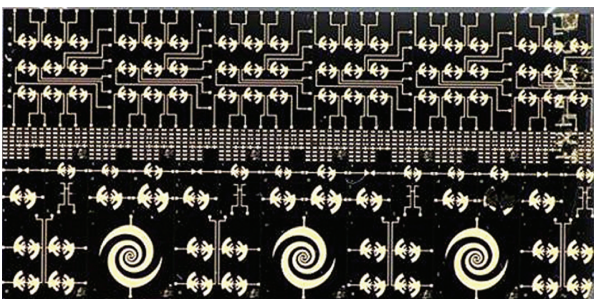

(a) The photograph of the THz monolithic antenna

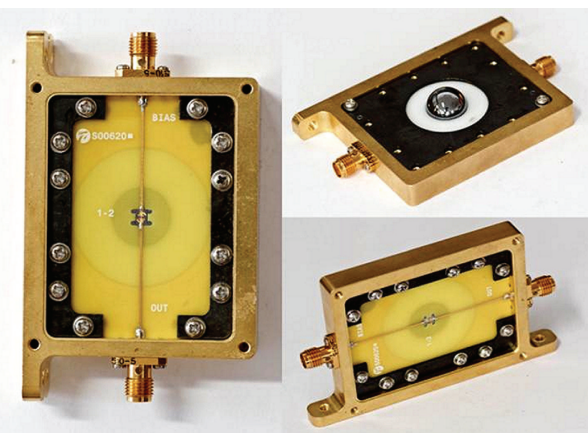

(b) The photograph of the $\mathrm{THz}$ monolithic antenna covered by a dielectric lens

FIGURE 15: THz wave planar integrated active microstrip antenna using micro-electromechanical systems (MEMSs).

national security, space exploration and communication, and so forth [39-46]. To realize $\mathrm{THz}$ transceiver system, antenna is an essential component. We often use horn antenna, lens antenna, and dielectric parabolic antenna, for $\mathrm{THz}$ systems. However, they are not easy to integrate with monolithic integrate circuits. Although the microstrip antenna has the merits of small volume, light weight, and easy integration with circuit, it is difficult to be processed in such high-frequency regions. MEMS technology opens the way to design of $\mathrm{THz}$ antennas, circuits, and systems. $\mathrm{THz}$ monolithic antenna fabricated using MEMS technology and covered by a dielectric lens, which can be considered a composite antenna, are designed, fabricated, and measured by our group, as shown in Figure 15.

Diodes have the functions of mixing and/or modulating the carrier-wave signal. It is an effective way to reduce the propagation path for detectors application by integrating the diode and microstrip antenna. The extended hyperhemispherical dielectric lens is used to increase the gain of the microstrip antenna. An antenna-coupled detector integrated with a dielectric lens is designed and fabricated up to $\mathrm{THz}$ range by our group. The planar microstrip log-spiral antenna and log-period antenna have been fabricated using micro-electromechanical systems (MEMSs) technology. The photographs of the antennas are demonstrated in Figure 15. The measured responses of the antenna-coupled detector working at different frequency bands are shown in Figure 16, which can be considered to determine the effective operating frequencies $[19,40]$. This detector gave a valid response from $12 \mathrm{GHz}$ to $110 \mathrm{GHz}$ frequencies. The results prove the validity and feasibility of the $\mathrm{THz}$ antenna designed using micro-electromechanical systems (MEMSs ) technology.

\section{Conclusion}

The advantages and disadvantages of microstrip antennas are discussed in this paper. In particular, three areas for further development of microstrip antennas are presented based on our previous works on microstrip antenna elements and arrays. Variety of microstrip antenna topologies and microstrip-antenna-based composite antenna are discussed, and 


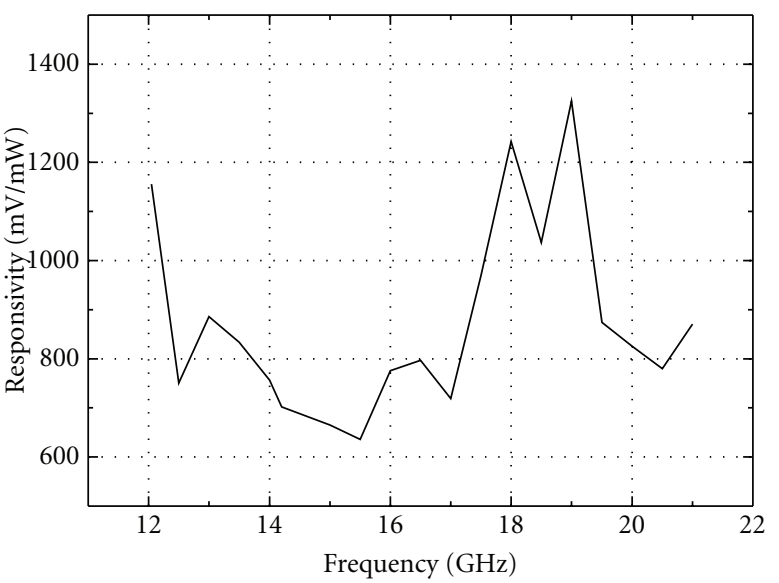

(a) Ku-band

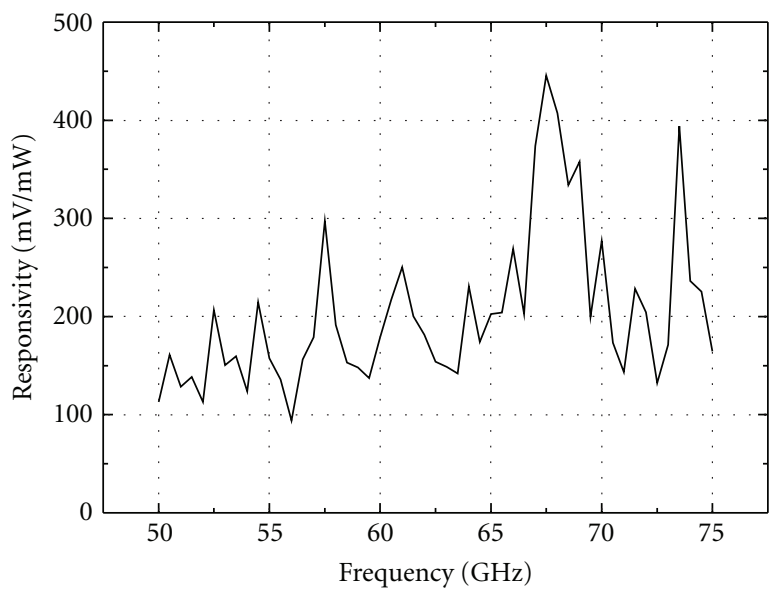

(c) V-band

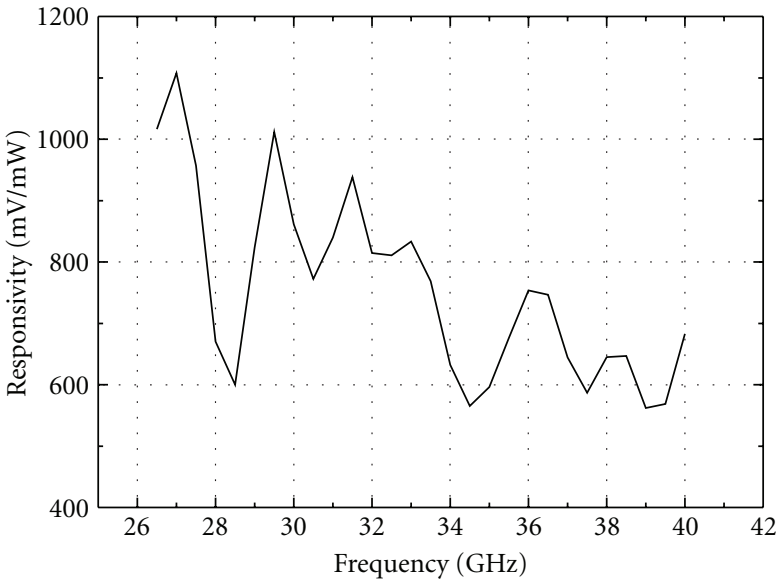

(b) Ka-band

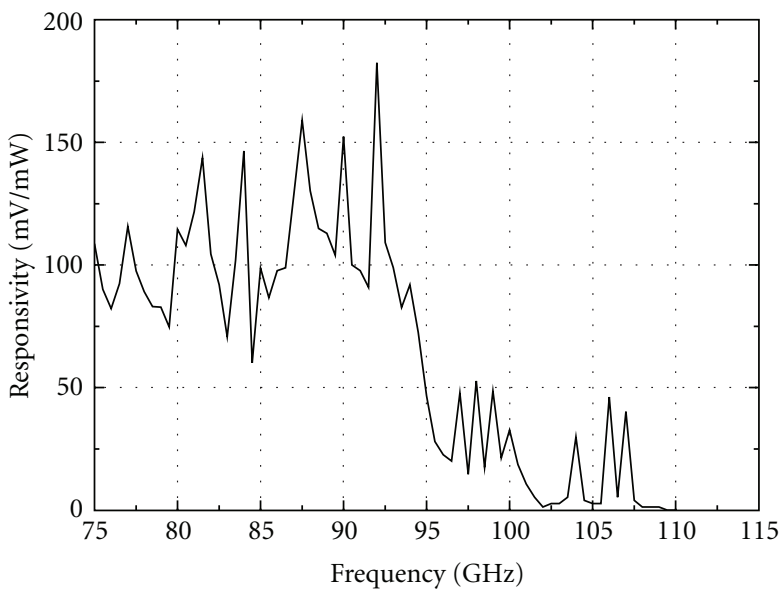

(d) W-band

FIGURE 16: Frequency responses test results of the THz wave planar integrated active microstrip antenna covered by a dielectric lens.

the advanced machining techniques pushing the microstrip antennas towards the highly integration of antenna/array and feeding network and the highly operating frequencies are described. To demonstrate the distinctive features of novel microstrip antennas, various antenna elements and arrays for different applications are presented. This paper has shown that the microstrip antennas are still very promising paradigm for civilian and military wireless applications.

\section{References}

[1] G. A. Deschamps, "Microstrip microwave antennas," in Proceedings of the 3rd USAF Symposium on Antennas, 1953.

[2] E. V. Byron, "A new flush-mounted antenna element for phased array application," in Proceedings of the Phased Array Antenna Symposium, pp. 187-192, 1970.

[3] J. Q. Howel, "Microstrip antennas," in Proceedings of the Digest of the International Symposium of the Antennas and propagation Society, pp. 177-180, 1972.

[4] I. J. Bahl and P. Bhartia, Microstrip Antennas, Artech House, 1980.

[5] J. R. James, P. S. Hall, and C. Wood, Microstrip Antenna Theory and Design, Peter Peregrinus, 1981.
[6] K. R. Carver and J. W. Mink, "Microstrip antenna technology," IEEE Transactions on Antennas and Propagation, vol. 1, no. 1, pp. 2-24, 1981.

[7] D. M. Pozar, "Microstrip antennas," Proceedings of the IEEE, vol. 80, no. 1, pp. 79-91, 1992.

[8] R. Garg, I. Bhartia, I. Bahl, and A. Ittipiboon, Micro-Strip Antenna Design Handbook, Artech House, Boston, Mass, USA, 2001.

[9] D. M. Pozar and B. Kaufman, "Increasing the bandwidth of a microstrip antenna by proximity coupling," Electronics Letters, vol. 23, no. 8, pp. 368-369, 1987.

[10] H. F. Pues and A. R. Van de Capelle, "Impedance-matching technique for increasing the bandwidth of microstrip antennas," IEEE Transactions on Antennas and Propagation, vol. 37, no. 11, pp. 1345-1354, 1989.

[11] A. Kaya and E. Y. Yüksel, "Investigation of a compensated rectangular microstrip antenna with negative capacitor and negative inductor for bandwidth enhancement," IEEE Transactions on Antennas and Propagation, vol. 55, no. 5, pp. 12751282, 2007.

[12] K. L. Wong and N. H. Hsu, "A broad-band rectangular patch antenna with a pair of wide slits," IEEE Transactions on Antennas and Propagation, vol. 49, no. 9, pp. 1345-1347, 2001. 
[13] S. I. Latif, L. Shafai, and S. K. Sharma, "Bandwidth enhancement and size reduction of microstrip slot antennas," IEEE Transactions on Antennas and Propagation, vol. 53, no. 3, pp. 994-1003, 2005.

[14] P. M. T. Ikonen, S. I. Maslovski, C. R. Simovski, and S. A. Tretyakov, "On artificial magnetodielectric loading for improving the impedance bandwidth properties of microstrip antennas," IEEE Transactions on Antennas and Propagation, vol. 54, no. 6, pp. 1654-1662, 2006.

[15] R. Cocooli, F. R. Yang, T. P. Ma, and T. Itoh, "Apertu-recoupled patch antenna on UCPBG substrate," IEEE Transactions on Microwave Theory and Techniaues, vol. 1, no. 47, pp. 21232130, 1999.

[16] L.-M. Si and X. Lv, “CPW-FED multi-band omni-directional planar microstrip antenna using composite metamaterial resonators for wireless communications," Progress in Electromagnetics Research, vol. 83, pp. 133-146, 2008.

[17] L. M. Si, H. Sun, Y. Yuan, and X. Lv, "CPW-fed com-pact planar UWB antenna with circular disc and spiral split ring resonators," in Progress in Electromagnetics Research Symposium, pp. 502-505, 2009.

[18] Y. Yuan, L.-M. Si, Y. Liu, and X. Lv, "Integrated logperiodic antenna for Terahertz applications," in International Conference on Microwave Technology and Computational Electromagnetics, pp. 276-279, 2009.

[19] L. Xin, M. Jinchao, Y. Yong, Y. Weihua, N. Hongbin, and G. Yafen, "Integrated active antennas in terahertz focal plane imaging system," in Proceedings of the International Workshop on Antenna Technology, pp. 157-163, 2011.

[20] Q. Xu, W. Zhang, H. Sun, and X. Lu, "Millimetre wave multipolarised microstrip antenna array and application example," IET Microwaves, Antennas and Propagation, vol. 4, no. 10, pp. 1525-1530, 2010.

[21] M. Wei, H. Deng, H. Sun, and Y. Liu, "Design of an $\mathrm{X} / \mathrm{Ka}$ dual-band co-aperture broadband microstrip antenna array," in Proceedings IEEE International Conference on Microwave Technology and Computational Electromagnetics, pp. 217-220, 2011.

[22] Y. Liu, X. Lu, Y. Yuan, Y. Chen, and L. Shi, "Integrated design and research of Ka-band electronically large mono-pulse planar antenna and feed system," in Proceedings of the 7th International Symposium on Antennas, Propagation and EM Theory (ISAPE'06), pp. 150-153, October 2006.

[23] Y. Liu, H. J. Sun, X. Lu et al., "Study of the millimeter microstrip monopulse antenna array in the dual-sensor system," in Proceedings of the 7th International Symposium on Antennas, Propagation and EM Theory (ISAPE '06), pp. 157160, October 2006.

[24] Y. An, X. Lv, and B. Gao, "Developing a kind of mi-crostrip array antenna with beam squint," in Proceedings of the 5th International Symposium on Antennas, Propagation and EM Theory, pp. 443-446, 2000.

[25] L. Yong, L. Xin, H. Zhao, and Y. Yuan, "Integrated design and research of novel KA-band circular polarized monopulse interrogator array antenna," in Proceedings of the IET International Radar Conference 2009, pp. 1-4, April 2009.

[26] H. A. Wheeler, "Fundamental limitations of small an-tennas," Proceedings of the IRE, vol. 35, pp. 1479-1484, 1947.

[27] L. J. Chu, "Physical limitations of omni-directional antennas," Journal of Applied Physics, vol. 19, no. 12, pp. 1163-1175, 1948.

[28] R. Azadegan and K. Sarabandi, "A novel approach for miniaturization of slot antennas," IEEE Transactions on Antennas and Propagation, vol. 51, no. 3, pp. 421-429, 2003.
[29] H. Mosallaei and K. Sarabandi, "Magneto-dielectrics in electromagnetics: concept and applications," IEEE Transactions on Antennas and Propagation, vol. 52, no. 6, pp. 1558-1567, 2004.

[30] P. M. T. Ikonen, S. I. Maslovski, C. R. Simovski, and S. A. Tretyakov, "On artificial magnetodielectric loading for improving the impedance bandwidth properties of microstrip antennas," IEEE Transactions on Antennas and Propagation, vol. 54, no. 6, pp. 1654-1662, 2006.

[31] P. M. T. Ikonen, K. N. Rozanov, A. V. Osipov, P. Alitalo, and S. A. Tretyakov, "Magnetodielectric substrates in antenna miniaturization: potential and limitations," IEEE Transactions on Antennas and Propagation, vol. 54, no. 11, pp. 3391-3399, 2006.

[32] P. Ikonen and S. Tretyakov, "On the advantages of magnetic materials in microstrip antenna miniaturization," Microwave and Optical Technology Letters, vol. 50, no. 12, pp. 3131-3134, 2008.

[33] J. Anguera, C. Puente, C. Borja, and J. Soler, "Frac-talshaped antennas: a review," in Wiley: Encyclopedia of RF and Microwave Engineering, K. Chang, Ed., vol. 2, pp. 1620-1635, 2005.

[34] L. Shi, H. Sun, X. Lu, C. Deng, and Y. Liu, "Study of the improved MM-Wave omni-directional microstrip antenna," in Proceedings of the 7th International Symposium on Antennas, Propagation and EM Theory (ISAPE '06), pp. 238-241, October 2006.

[35] L. Shi, H. Sun, and X. Lu, "A composite antenna with wide circularly polarized beamwidth," Microwave and Optical Technology Letters, vol. 51, no. 10, pp. 2461-2464, 2009.

[36] L. Shi, H. Sun, W. Dong, and X. Lv, "A dual-band multifunction carborne hybrid antenna for satellite communication relay system," Progress in Electromagnetics Research, vol. 95, pp. 329-340, 2009.

[37] Y. Chen, H. Sun, and X. Lv, "Novel design of dual-polarization broad-band printed L-shaped probe fed microstrip patch antenna for SAR applications," in IET International Radar Conference 2009, pp. 1-4, April 2009.

[38] L. M. Si, H. J. Sun, and X. Lv, "Numerical simulations of backward-to-forward leaky-wave antenna with composite right/left-handed coplanar waveguide," Chinese Physics Letters, vol. 27, no. 3, Article ID 034106, 2010.

[39] L.-M. Si, H.-J. Sun, and X. Lv, “THz leaky-wave antenna with high-directivity and beam-steering using CPW CRLH metamaterial resonators," in Proceedings of the 3rd International Symposium on Photoelectronic Detection and Imaging, Beijing, China, 2009.

[40] Y. Liu, L. M. Si, S. Zhu, and H. Xin, "Experimental realization of an integrated $\mathrm{THz}$ electromagnetic crys-tals (EMXT) Hplane horn antenna," Electronics Letters, vol. 47, no. 2, pp. 8082, 2011.

[41] L. M. Si, Y. Liu, S. H. Zhu, and H. Xin, "Integrated THz horn antenna using EBG structures," in Proceedings of the IEEE International Symposium on Antennas and Propagation and USNC/CNC/URSI National Radio Science Meeting, University of Colorado at Boulder, 2011.

[42] Y. Liu, Y. Yuan, X. Lv, and L.-M. Si, "Design of $0.5 \mathrm{THz}$ 2D square lattice EBG waveguide transmission line and power-divider using MEMS technology," in Proceedings 3rd International Symposium on Photoelectronic Detection and Imaging, vol. 7385, Beijing, China, 2009.

[43] L.-M. Si, Y. Yong, H.-J. Sun, and L. Xin, "Characterization and application of planar terahertz narrow bandpass filter with metamaterial resonators," in Proceedings of the International 
Workshop on Metamaterials, pp. 351-354, Nanjing, China, 2008.

[44] L. M. Si and X. Lv, "Terahertz waves hairpin microstrip bandpass filter and its application to overlaid dielectric material detection," Modern Physics Letters B, vol. 22, no. 29, pp. 2843$2848,2008$.

[45] L.-M. Si, H.-J. Sun, and X. Lv, “Theoretical investigation of terahertz amplifier by carbon nanotubes within transmission line metamaterials," Microwave and Optical Technology Letters, vol. 53, no. 4, pp. 815-818, 2011.

[46] W. Hong, "Millimeter wave and $\mathrm{THz}$ communications in China," in Proceedings of the IEEE International Microwave Symposium Digest (MTT'11), pp. 1-4, 2011. 

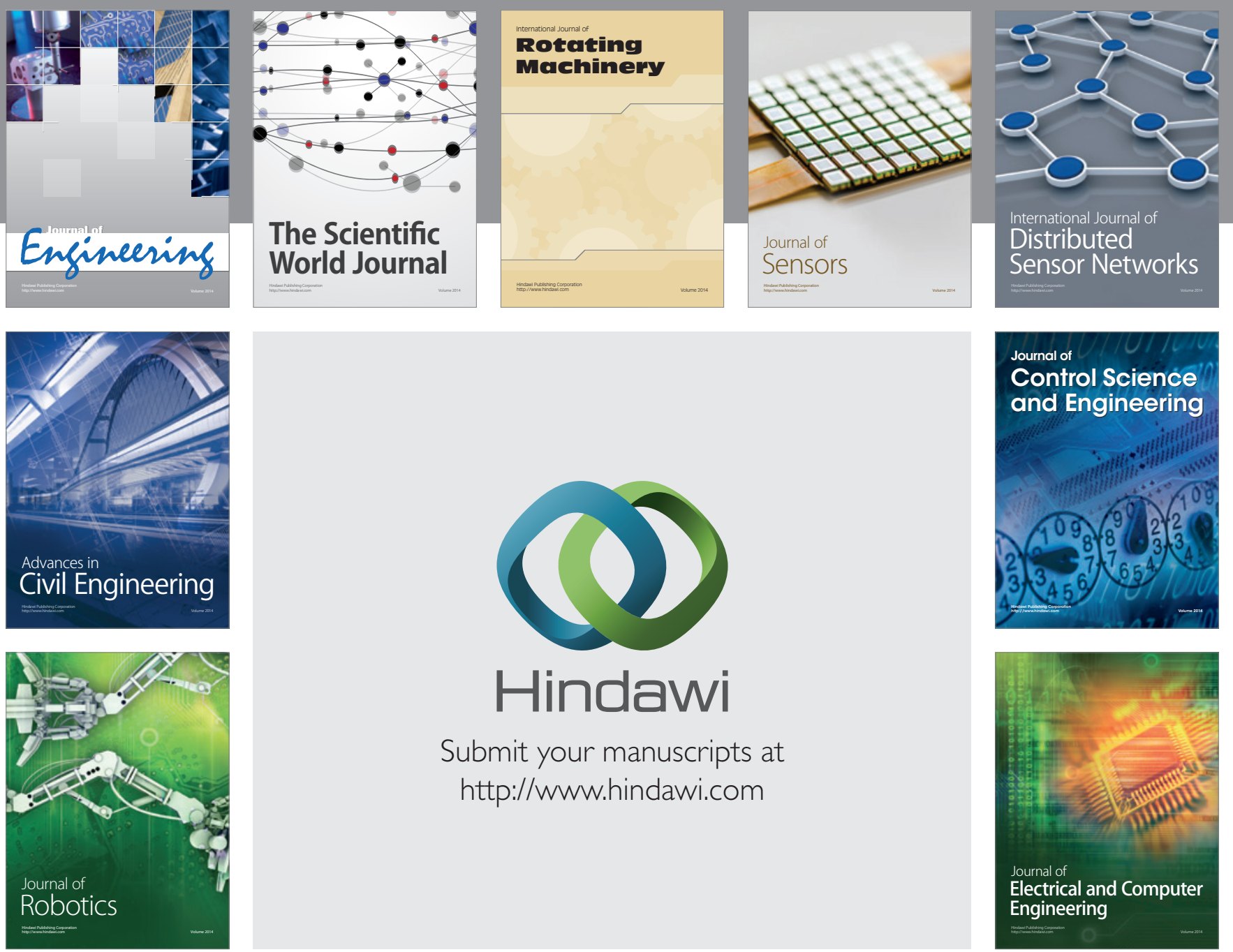

Submit your manuscripts at

http://www.hindawi.com
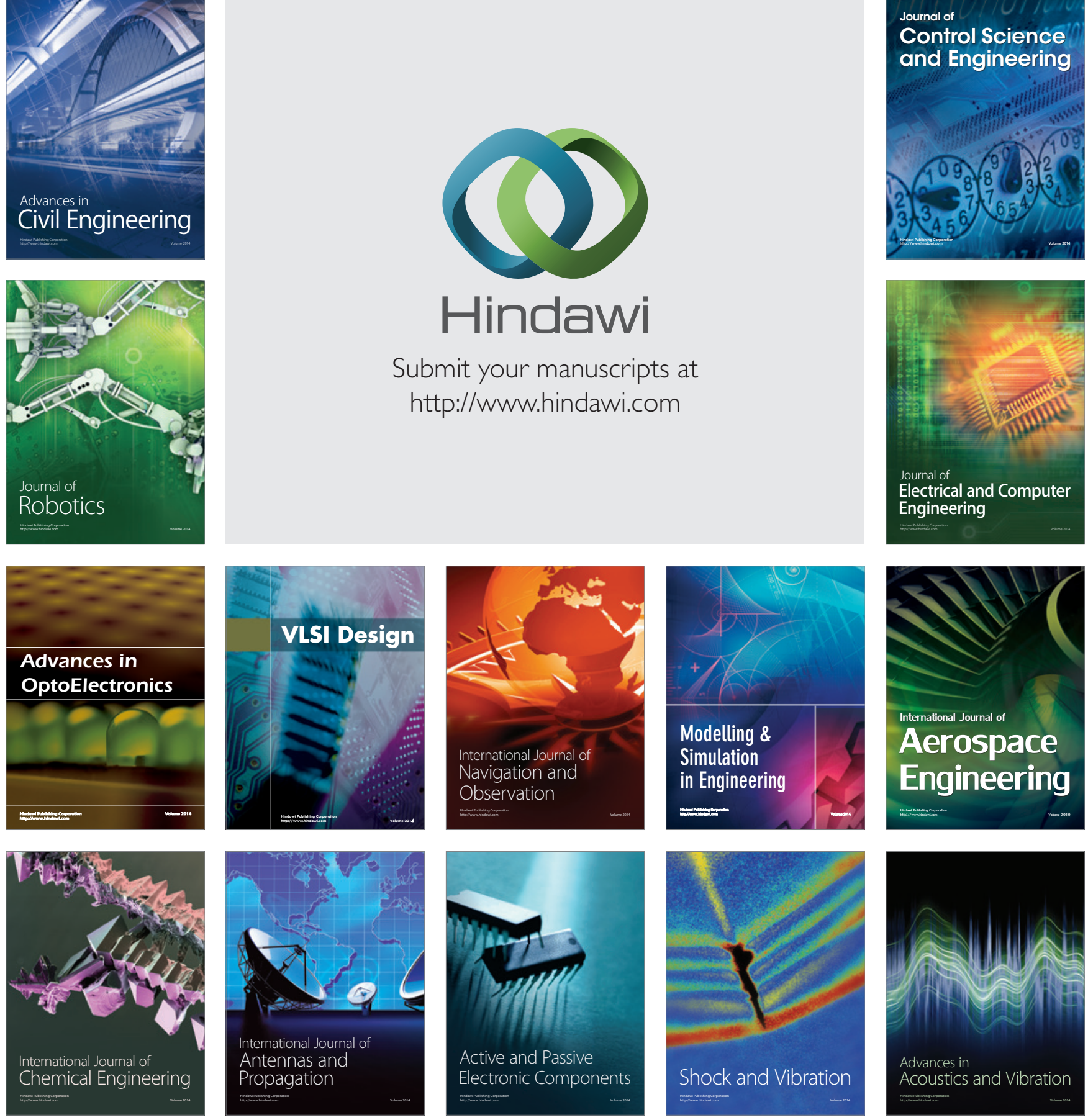